\title{
Evaluation of a school based comprehensive sexuality education program among very young adolescents in rural Uganda
}

Elizabeth Kemigisha ${ }^{1,2^{*+}}$ D , Katharine Bruce ${ }^{1 \dagger}$, Olena Ivanova ${ }^{3}$, Els Leye ${ }^{2,4}$, Gily Coene ${ }^{4}$, Gad N. Ruzaaza ${ }^{1}$, Anna B. Ninsiima ${ }^{4}$, Wendo Mlahagwa', Viola N. Nyakato ${ }^{1}$ and Kristien Michielsen ${ }^{2}$

\begin{abstract}
Background: Limited research has been conducted on the effectiveness of sexuality education for very young adolescents (VYAs) ages 10-14 years in Sub-Saharan Africa. Furthermore, evaluations of sexuality education programs often report outcomes of risky sexual practices, yet positive aspects of sexuality are hardly studied and rarely reported. This study evaluates the effectiveness of a Comprehensive Sexuality Education (CSE) intervention for VYAs in Uganda, analyzing both positive and negative outcome indicators.

Methods: We conducted a mixed methods study, incorporating a cluster randomized trial (NCT03669913) among pupils in 33 randomly selected primary schools in Mbarara district. This was followed by a qualitative evaluation of the intervention in 4 schools that included 14 in-depth interviews and 3 focus group discussions distributed among pupils, teachers and parents. Quantitative data were analyzed using ordered logistic regression to compare differences in the change from baseline to endline between the intervention and control arms. We conducted bivariate analysis and multiple regression analysis controlling for key covariates, including age, gender, school location (rural vs urban), truancy, and orphanhood. Qualitative data were analyzed by thematic approach using ATLAS TI.
\end{abstract}

Results: Between July 2016 and August 2017, 1096 pupils were recruited. Outcomes were studied among 380 pupils in the intervention arm and 484 pupils in the control arm. The proportion of pupils who ever had sex increased from 9 to $12.1 \%$ in intervention compared to 5.2 to $7.4 \%$ in the control group between baseline and endline, however the differences between groups were not statistically significant. We found greater improvements in sexual and reproductive health (SRH) knowledge among intervention schools (AOR: 2.18, 95\% Cl: 1.66-2.86) and no significant differences in self-esteem, body image or gender equitable norms. Qualitative evidence echoes perceived SRH knowledge acquisition, increased their perception of SRH related risks, and intentions to delay sexual intercourse to prevent unwanted pregnancy, HIV and other STIs.

Conclusion: This study demonstrates that CSE can improve SRH knowledge and behavioral intentions among VYAs in Uganda. These results further emphasize the importance of initiating sexuality education before most adolescents have started engaging in sexual activity, enabling them to make informed decisions in the future.

(Continued on next page)

\footnotetext{
* Correspondence: ekemigisha@must.ac.ug

${ }^{\dagger}$ Elizabeth Kemigisha and Katharine Bruce contributed equally to this work.

${ }^{1}$ Mbarara University of Science and Technology, P.O. Box 1410, Mbarara,

Uganda

${ }^{2}$ International Centre for Reproductive Health, Faculty of Medicine and

Health Sciences, Ghent University, Ghent, Belgium

Full list of author information is available at the end of the article
}

(c) The Author(s). 2019 Open Access This article is distributed under the terms of the Creative Commons Attribution 4.0 International License (http://creativecommons.org/licenses/by/4.0/), which permits unrestricted use, distribution, and reproduction in any medium, provided you give appropriate credit to the original author(s) and the source, provide a link to the Creative Commons license, and indicate if changes were made. The Creative Commons Public Domain Dedication waiver (http://creativecommons.org/publicdomain/zero/1.0/) applies to the data made available in this article, unless otherwise stated. 
(Continued from previous page)

Trial registration: NCT03669913, registered retrospectively on September 13th, 2018.

Keywords: Comprehensive sexuality education, Sexual and reproductive health, Evaluation, Very young adolescents, Uganda

\section{Background}

Sub-Saharan Africa (SSA) has a largely youthful population whereby in 15 countries, more than half of the population is below 18 years [1]. Adolescents between 10 to 19 years make up at least 23\% of the population in SSA and these face the highest burden of Sexual and Reproductive Health (SRH) risks [2-4]. It is estimated that in 2016, 777, 000 births occurred among young adolescents ages 10 to 14 in developing countries, $58 \%$ of which were in Africa [5]. In Uganda, over a third of the population are adolescents [6], most of whom face great challenges related to their sexual health and wellbeing. According to Uganda's 2016 Demographic and Health Survey (UDHS), 25\% of girls begin child-bearing by the age of 19 years [6]. Adolescent pregnancy is associated with immediate health risks, including pre-term delivery, operative delivery, eclampsia and poor infant survival, as well as the long-term risks of dropping out of school and the financial burden of childbearing $[7,8]$. Furthermore, the HIV prevalence in Uganda remains high. About 1.2 million adults and 95,000 children below 15 years are living with HIV/AIDS, with a prevalence of 6.2 and $0.5 \%$ respectively [9]. Many Ugandan adolescents lack the knowledge necessary to make informed decisions about their SRH. The 2016 DHS found that only $46 \%$ of females and $45 \%$ of males aged 15-24 had comprehensive knowledge about HIV prevention [6]. These SRH issues demonstrate a complex intersection of limited resources, lacking SRH knowledge, and prohibitive cultural norms, all of which influence SRH behaviors [10, 11].

Most research and country-level data in Uganda focuses on older adolescents, aged 15 and above, while very young adolescents are often neglected in this field. Interventions usually focus on older adolescents who may already be sexually active, yet interventions that focus on younger adolescents who have not experienced sexual debut may be more effective in preparing these adolescents to make informed preventive choices. Comprehensive Sexuality Education (CSE) could be an effective and feasible approach to improve adolescent SRH knowledge and outcomes. UNESCO defines CSE as "an age-appropriate, culturally relevant approach to teaching about sexuality and relationships by providing scientifically accurate, realistic, non-judgmental information" [12]. A meta-analysis of 33 school-based CSE programs implemented in low and middle income countries showed that CSE can increase sexual health knowledge and safer sexual practices such as delayed sexual debut, increased condom use and a reduced number of sexual partners [13]. However, few such studies have been published on the Ugandan context. In the two school-based CSE evaluation studies found in Uganda, effectiveness was limited, due to challenges in implementation, lack of fidelity to the program, and poorly defined outcome indicators [14-16]. The majority of existing studies, in Uganda and elsewhere, focus on older adolescents, and there is a need for further research among young adolescents where such programs could be more effective [17]. Furthermore, most studies only evaluate risky or negative behaviors and attitudes. Few measure positive behavioral components related to CSE interventions such as life skills, self-esteem and gender equitable norms [18].

This paper evaluates the effectiveness of a comprehensive SRH intervention implemented in 33 primary schools for very young adolescents (VYAs) in South Western Uganda. The evaluation explored changes in knowledge and behavior, in addition to more novel measures of positive attributes of sexual health including self-esteem, body image, and gender equitable norms.

\section{Methods \\ The intervention}

The intervention was based on behavioral theories including the Theory of Planned Behavior and the Social Ecological Model to promote changes in knowledge, attitudes and practices related to sexual health $[19,20]$. The intervention was developed following extensive document review of international guidance on sexuality education [12], standards for sexuality education in Europe [21] and curriculum for primary schools in Uganda for primary level 4-7 (between an average age of 9 to 12 years) [22]. The lessons employed diverse classroom activities including role playing, group discussions, dissecting case studies, individual written activities and traditional lectures. A Community Advisory Board (CAB) consisting of educational, religious and cultural leaders in Mbarara helped to provide insight into the cultural and religious appropriateness of all content delivered. There were $8 \mathrm{CAB}$ members in total. The $C A B$ met with the research team a total of 4 times (prior to the baseline survey, prior to the start of the intervention, during the course of the intervention and at the dissemination of findings). The CAB was instrumental in guiding the implementation process and recommending changes in the evaluation questionnaire and lesson content to ensure cultural appropriateness. 
Eleven lessons were delivered that consisted of the following topics: puberty, relationships and emotions, decision making, self-esteem skills, reporting of physical and sexual violence, knowing one's rights, sexually transmitted infections, HIV/AIDS and stigma, prevention of pregnancy, sexuality and gender, and sexuality and media influence. Volunteer undergraduate university students were trained in facilitation skills for each lesson prior to its delivery in schools. There were a total of 22 educators at the beginning of the intervention of which 13 were female and 9 were male. During the intervention, five educators graduated from university and were replaced with other university students. Each of the eleven lessons was delivered within $1-2 \mathrm{~h}$ in each of the schools to the combined upper classes of primary five, six and/or seven. However, sometimes two lessons were combined and delivered in one session. A total of 8 visits were made on a monthly basis to each of the 15 intervention schools to deliver the lessons. The delivery of these lessons was monitored by observers including teachers at each school and lecturers and post graduate students from Mbarara University. Throughout the implementation, key aspects of CSE were encouraged and monitored, including age appropriateness, gender sensitive content and nonjudgmental information delivery. Delivery of the intervention occurred between August 2016 and April 2017.

\section{Evaluation of the intervention Study design}

We conducted a mixed methods study to evaluate the effectiveness of this intervention, employing a cluster randomized trial (NCT03669913) as well as postintervention qualitative interviews and focus group discussions among study participants in the intervention arm. The study assessed changes in sexual health knowledge, sexual behavior, body image, self-esteem and gender equitable norms over a period of 1 year. The study adhered to CONSORT guidelines for reporting of clinical trials [23].

\section{Quantitative methods \\ Sample size}

The cluster randomized trial involved 15 intervention schools and 18 control schools. These were mainly publically funded schools $(n=31)$ with a few private schools $(n=2)$ which is representative of the local context. Sample size estimation was based on simulations in R software. We hypothesized a $10 \%$ greater increase in scores for main outcomes between baseline and end-line assessments in the intervention arm compared to the control arm. Taking into account the intra-class correlation calculated from the pilot test among 105 pupils, it was determined that a minimum sample size of 846 would be needed to measure a difference of $10 \%$ between groups (reference $50 \%$ ) with a power of $90 \%$. With an estimated drop-out rate of approximately $20 \%$ between baseline and endline assessments, which were 1 year apart, the minimum sample size at baseline was determined to be 1100 pupils in 33 clusters. Within each school, an average of 34 pupils were included in our initial sample.

\section{Selection of participating schools and individual study participants}

The study was conducted within primary level schools in Mbarara district, found in South Western Uganda. A list of 248 primary schools located in both rural and urban regions was available from district records. We eliminated schools that had no upper classes (primary 5 to 7), and schools that offer unique services, including schools for children with hearing and visual impairments. The names of the rest of the schools were entered into an Excel spreadsheet and a formula was developed to randomly select the required 33 schools for the study. Then an independent statistician randomly assigned each of the 33 schools to the treatment or control arm, using a new Excel formula. Research assistants (RAs) selected the final sample of pupils per school from class registration lists using systematic sampling methods and substituting pupils who were absent on the interview day.

\section{Study procedures}

To assess the effectiveness of the intervention, we developed a questionnaire (ref: Additional file 1, supplementary material) which was piloted among 105 adolescents. The questionnaire was developed in English and administered in English and in the local language (Runyankole). RAs interviewed students and recorded their responses on paper surveys, which were later entered into a computer database. All RAs were fluent in both languages and administered questionnaires based on each adolescent's language preference. Additionally, student's names were not included on the paper survey on which RAs recorded their responses. Instead, we used unique identification numbers in an effort to maintain privacy.

Pupils were interviewed at baseline before the start of the intervention in June and July 2016. After the ninemonth intervention was completed, pupils were interviewed again in June and July 2017. Efforts were made to trace pupils who were not available at the day of the interview but could be located within 1 month.

\section{Outcome measures}

\section{Sexual and reproductive health knowledge}

SRH knowledge was measured based on knowledge of puberty, HIV/STIs and pregnancy prevention. The students were asked questions based on the planned intervention material and were expected to come up with 
correct answers (as opposed receiving multiple choice questions). This included knowledge on how HIV/AIDS can be acquired, such mother to child transmission, unsterilized instruments or unprotected sex (score 0-4), types of common Sexually Transmitted Infections, such as chlamydia, HIV, gonorrhea and syphilis (score 0-4), knowledge of physical changes during puberty in boys, such as growth of beards, enlargement of genitalia, and acne (score 0-6) and in girls, such as enlargement of breasts, pubic hair and enlargement of hips (score 0-7), and knowledge about ways to prevent pregnancy, such as abstinence and other contraceptive methods (score 0-4). We adapted some of these questions on STI/HIV/Contraception awareness from the WHO illustrative questionnaire for interviews with young people [24]. Due to the age group in question, we also added relevant questions on pubertal changes occurring in boys and girls.

\section{Sexual wellbeing and attitudes}

Self-esteem scores were estimated using 7 of 10 items of the Rosenberg (1965) self-esteem scale [25]. Body image scores were estimated using 5 of the 6 items of the Body Image States Scale (BISS-6) [26]. Gender equitable norms scores were estimated using 11 items. Six of these items were adapted from the Attitudes towards Women Scale for Adolescents (AWSA) [27] and 5 items were developed to suit the respondents' age and the Ugandan context. We have described these scales in detail in a previous publication [28].

\section{Sexual behavior}

Sexual behavior was defined as experience with consensual heterosexual intercourse. Given the political climate around adolescent sexuality and homosexuality in Uganda, we were unable to ask VYAs about their sexuality beyond heterosexual intercourse. Owing to the fact that we were dealing with very young adolescents, interviewers selectively asked questions about sexual activity to only participants who reported that they had been to a private place with a peer of the opposite sex. RAs defined heterosexual sex for pupils as "a boy inserting a penis into the vagina." Sexual behavior was then classified using a binary yes/no question regarding engagement in sexual activity prior to the study or within the intervention year. Sexual behavior included early sexual onset as well as risky sexual practice (sex without a condom). Given the young age of our study population, those who were already engaging in sex reflected early sexual onset, which we also considered risky sexual behavior.

\section{Other variables}

We assessed relevant pupil characteristics including age, gender, socio-economic status, orphanhood status and truancy. A socio-economic score was developed based on household water source, distance from water source, household possessions and pupil possessions including shoes and pairs of school uniforms, as we described previously [28]. We also assessed truancy, which was defined as missing school for any reason other than illness. We selected individual and interpersonal variables that could affect the key outcomes among very young adolescents.

\section{Quantitative data analysis}

Statistical analyses were conducted using Stata ${ }^{\circ}$ (College Station, Texas, USA). Baseline characteristics at the cluster (school) and individual levels were summarized using group totals and proportions. All outcome variables were analyzed as ordinal categorical variables, with the exception of sexual behavior which was analyzed as a binary variable. Where there were outliers, we grouped the extreme ends of the scales to address skewed data. Specifically, the sexual health knowledge scale was collapsed from 22 categories into 20, gender equitable norms from 30 categories into 24 , self-esteem from 18 categories into 14 , and body image from 18 categories into 14. Cronbach alpha scores for individual scales ranged from 0.61 to 0.68 at baseline, and from 0.61 to 0.76 at endline. An interaction variable was created using the round variable (baseline vs endline) and study arm variable (intervention vs control). We then used an ordered logistic regression to compare differences in the change from baseline to endline between the intervention and control arms, also known as the "difference in differences" method [22]. We conducted both a univariate analysis and a multiple regression analysis controlling for key covariates, including age, gender, school location (rural vs urban), truancy, and orphanhood. We conducted a second multivariate analysis splitting the groups by gender, to assess whether there was a difference in the treatment effect between boys and girls.

\section{Qualitative methods}

The qualitative interviews were conducted in a broader context of the study as part of a process evaluation of the CSE intervention [29]. Table 1 is a summary of participant characteristics. Fourteen In-Depth Interviews (IDIs) using an open-ended interview guide were conducted with 4 pupils, 8 teachers and 2 parents. The participants were selected purposively. The pupils and teachers were stratified into two sub-categories; that is the rural and urban schools. The IDI guides comprised open-ended questions which elicited responses related to experiences with CSE, SRH knowledge, SRH behavior and sexual well-being of young adolescents. The interviews were conducted in English for pupils and teachers and Runyankole for parents. 
We conducted three focus group discussions (FGDs); one with parents and two with pupils comprising 8-12 participants selected purposively. The pupils were identified from within the schools where the CSE intervention was conducted and the schools were stratified into rural and urban settings. The FGDs were conducted in English for the pupils and Runyankole for the parents. The FGDs were conducted to help to establish overall experiences, opinions and attitudes towards the CSE intervention. The FGD guide and IDI guides were pretested to check for accuracy and consistency and to improve validity before the actual data collection began. The IDI and FGD consent forms were translated from English to Runyankole for FGD participants who could not comprehend the English language. Trained research assistants were recruited to conduct the data collection.

\section{Qualitative data analysis}

The IDIs and FGDs were audio-recorded. The recordings were transcribed verbatim and reviewed in comparison to field notes. Thematic analysis was used for qualitative data analysis. A code list was generated based on the objectives of the study and the outcome variables of the quantitative survey. Coding and analysis were done using Atlas.ti software, where segments from the data were copied and assigned to the generated codes. Texts were coded and clustered along emergent themes in the data and these were later organized according participant's experiences of the CSE intervention. The qualitative data were presented in narrative form.

\section{Ethical considerations}

The study was conducted in accordance with the principles defined by the World Health Assembly of 1975 with regard to the ethics principles of research involving

Table 1 Characteristics of the qualitative study sample

\begin{tabular}{lll}
\hline Study sample & Characteristics & Number of participants \\
\hline IDls & & 2 \\
Pupils $(n=4)$ & Female & 2 \\
Teachers $(n=8)$ & Male & 2 \\
& Male & 6 \\
& Female & 4 \\
& Urban School & 4 \\
Parents & Rural school & 1 \\
& Female & 1 \\
FGDs & Male & 8 \\
Pupils $(n=2)$ & Rural school & 8 \\
Parents $(n=1)$ & Urban school & 12 \\
\hline
\end{tabular}

human subjects. Ethical approval was received from the Mbarara University Research Ethics Committee (REF MUIRC/7), Uganda National Council of Science and Technology (SS 4045), Ghent University Hospital Ethics Board and registered with clinicaltrials.gov (NCT03669913). We obtained written informed consent from the school head teachers and parents/guardians and assent from pupils prior to data collection. Authorization was obtained from the local ethics board to allow teachers to consent as legal guardians for pupils if a parent was not available at the time of the interview, and efforts were made to inform these parents of their child's participation. A psychiatrist was available to offer counselling to adolescents whenever this was required. The involvement of the psychiatrist was part of the ethical obligation to address any emerging adverse events such as psychological distress and this did not in any way interfere with the intervention activities. Furthermore the information collected from counselling sessions was not used in the study.

\section{Results}

In this section, we will report the main findings from the impact evaluation using three main outcomes: SRH knowledge, SRH behavior, and sexual wellbeing and attitudes. Each outcome measured quantitatively will be supported by the qualitative findings from interviews and FGDs.

\section{Characteristics of study participants}

Pre and post intervention surveys were conducted in June and July of 2016 and 2017 among young adolescents in 33 primary schools in Mbarara district, Uganda. A total of 1096 adolescents (476 in intervention and 620 in control schools) were interviewed at baseline and 864 (380 in intervention and 484 in control schools) were interviewed at endline (Fig. 1). The total attrition rate from baseline to endline was $20.6 \%$. The reasons participants were lost to follow up were changing schools (68.5\%), dropping out of school (22.5\%), getting married $(0.9 \%)$ and others $(8 \%)$. The attrition rate was not significantly different between treatment and control groups. Of the 33 participating schools, those from the rural areas represented $13 / 15$ of schools in the intervention arm and 14/18 in the control. Other characteristics of the schools (clusters) are included in Table 2. At endline, participants' ages ranged from 11 to 15 years.

The mean age, gender distribution, and orphanhood status were similar among intervention and control arms. However, there were significant differences in socio-economic level, religion and school location (rural vs urban) between the intervention and control arms at baseline (Table 3). 


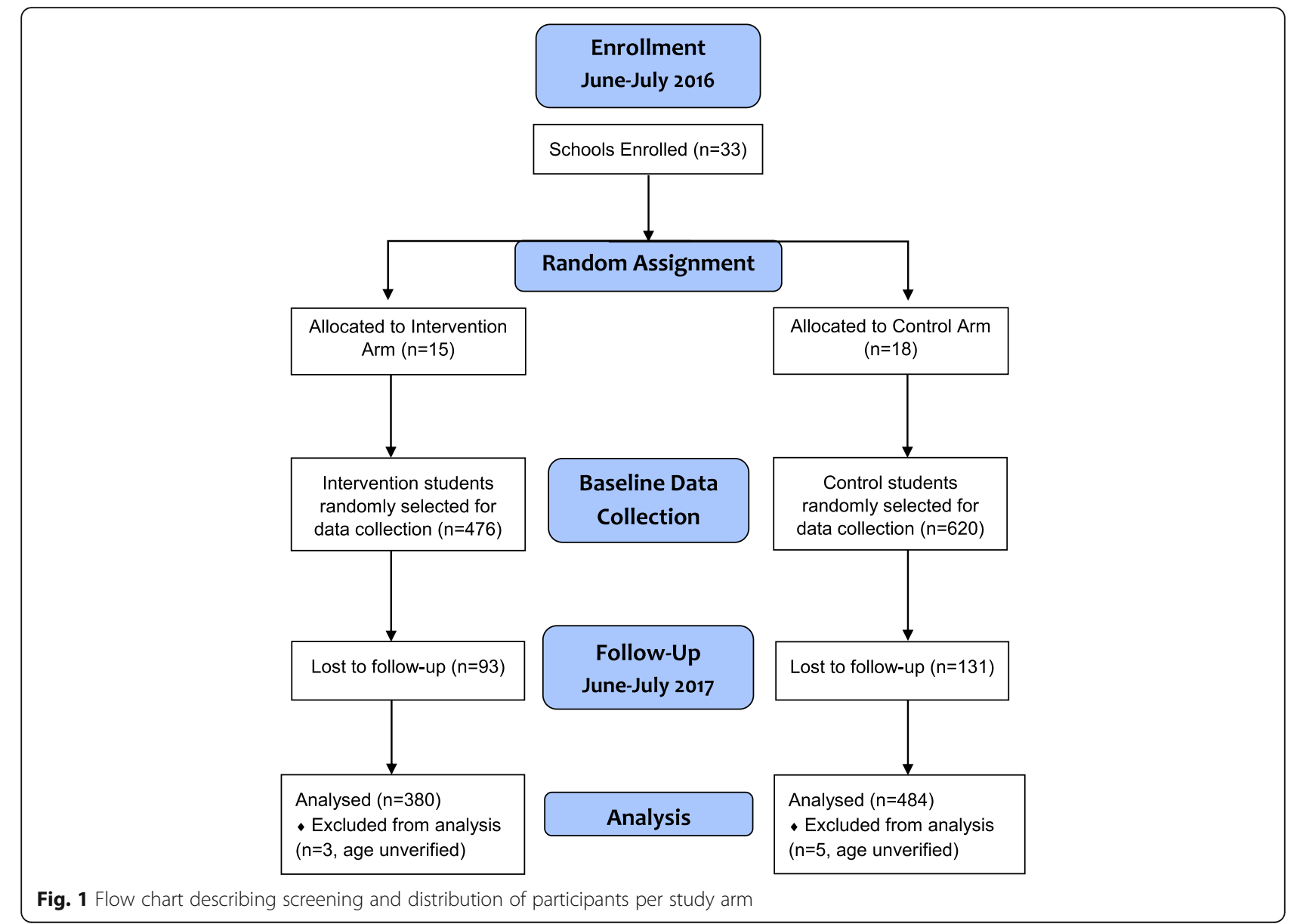

\section{Effectiveness of the intervention}

\section{Sexual health knowledge}

The median score for SRH knowledge changed from 8 to 12 in the intervention arm as compared to 8 to 11 in the control arm (Table 4). On further analysis, Sexual Health Knowledge scores improved significantly more among the treatment group compared to the control group. At a bivariate level, the treatment group had 2.14 $(p<0.001)$ times the odds of having greater score improvements than the control group. At multivariate analysis when adjusting for relevant covariates, the treatment group was $2.17(\mathrm{p}<0.001)$ times as likely to have greater improvements in SRH knowledge scores (Table 5). When stratifying by gender, we found that the treatment effect was significant in both boys and girls.

\section{Sexual wellbeing and attitudes}

The median scores for gender equitable norms, body image and self-esteem did not differ between intervention and control groups at baseline or at endline (Table 4). We did not find any statistically significant differences in changes of gender equitable norms, body image, or selfesteem scores between the intervention and control
Table 2 Description of participating schools (clusters)

\begin{tabular}{lll}
\hline School characteristics & $\begin{array}{l}\text { Intervention } \\
n=15\end{array}$ & $\begin{array}{l}\text { Control } \\
n=18\end{array}$ \\
\hline $\begin{array}{lll}\text { School location } \\
\text { Rural }\end{array}$ & 13 & 14 \\
Urban & 2 & 4 \\
School care & 14 & 12 \\
Day school & 1 & 6 \\
Day and boarding & & \\
School sponsor & 15 & 16 \\
Government & 0 & 2 \\
Private & & \\
School religious background & 11 & 7 \\
Anglican & 3 & 2 \\
Catholic & 1 & 1 \\
Moslem & 0 & \\
Pentecostal & &
\end{tabular}


Table 3 Baseline social and demographic characteristics for the intervention and control groups

\begin{tabular}{|c|c|c|c|}
\hline \multirow[t]{2}{*}{ Characteristics } & \multicolumn{3}{|l|}{ Baseline } \\
\hline & Total n (\%) & Intervention & control \\
\hline Age (mean, SD) & $12.1(1.13)$ & $12.2(1.03)$ & $12.1(1.20)$ \\
\hline \multicolumn{4}{|c|}{ Gender } \\
\hline Male & $357(41.3)$ & $147(38.7)$ & $210(43.4)$ \\
\hline Female & $507(58.7)$ & $233(61.3)$ & $274(56.6)$ \\
\hline \multicolumn{4}{|c|}{ Socio-economic level ${ }^{a}$} \\
\hline Low & 272 (31.8) & $116(30.8)$ & 156 (32.6) \\
\hline Medium & $394(46.0)$ & $194(51.4)$ & $200(41.8)$ \\
\hline High & $190(22.2)$ & $67(17.8)$ & $123(25.6)^{*}$ \\
\hline \multicolumn{4}{|l|}{ Parent alive/not } \\
\hline One/both dead & $147(17.0)$ & $72(19.0)$ & 75 (15.5) \\
\hline Both alive & 717 (83.0) & $308(81.0)$ & 409 (84.5) \\
\hline \multicolumn{4}{|l|}{ Education level } \\
\hline Primary 5 & $438(50.7)$ & 198 (52.1) & 240 (49.6) \\
\hline Primary 6 & $426(49.3)$ & $182(47.9)$ & $244(50.4)$ \\
\hline \multicolumn{4}{|l|}{ School location } \\
\hline Rural & 719 (83.2) & 337 (88.7) & $382(78.9)^{* *}$ \\
\hline Urban & 145 (16.8) & $43(11.3)$ & $102(21.1)$ \\
\hline
\end{tabular}

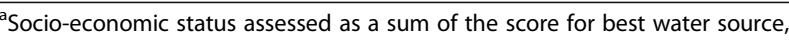
housing possessions and pupil possessions such as shoes or school uniform pairs with a possible score range of 1-25, median of 8.1. Scores were categorized as "Low" if scores were 1-5,"medium" if scores were 6-10, and "high" if scores were 11 or higher

$* P=<0.01{ }^{*} P=<0.001$

groups (Table 5). This was the case in both the bivariate and multivariate analyses as well as among both genders.

\section{Sexual behavior}

In the intervention group, 34 (9\%) pupils at baseline and $46(12 \%)$ at endline reported that they had ever had sex. In the control group, 25 (5\%) pupils at baseline and 36 (7\%) at endline reported that they had ever had sex
(Table 4). We did not find any statistically significant differences between the intervention and control groups in terms of changes in sexual behavior. This was the case in both the bivariate and multivariate analyses, as well as among both genders.

\section{Findings from the qualitative analysis}

The qualitative findings reveal that study participants recalled many of the CSE topics they had been exposed to during the intervention. Participants reported that they benefited from the topics related to puberty and what they could expect during that life stage. While some pupils reported prior knowledge of some of these topics in their regular classroom hours, they reported that they had gained new information from the CSE session that changed their beliefs and attitudes around puberty and pregnancy. Some examples include:

"...I didn't know that at 12 years a boy can make a girl pregnant." (Student, FGD, rural school)

\section{"I learnt that even before menstruation you can get pregnant. It was new to me." (Student, FGD, rural school)}

"There is when you would get wet dream and you refuse to go to school but now I know it's normal." (Student, IDI, rural school)

The participants reported that the CSE lessons helped them understand body changes and maintenance of personal hygiene, and that they felt more comfortable handling these changes during puberty. They were now able to relate with the opposite sex more comfortably; they became more receptive of CSE information without feeling tense or embarrassed and reported being able have open discussions about these pubertal changes:

Table 4 Comparison of sexual health outcomes among young adolescents (unadjusted)

\begin{tabular}{|c|c|c|c|c|}
\hline & \multicolumn{2}{|c|}{ Intervention } & \multicolumn{2}{|l|}{ Control } \\
\hline & Baseline & Endline & Baseline & Endline \\
\hline Sexual Health Knowledge ${ }^{\mathrm{a}}$, Median (Mean) & $8(8.1)$ & $12(12.4)$ & $8(8.4)$ & $11(11.1)$ \\
\hline Gender equitable norm ${ }^{\mathrm{b}}$ Median (Mean) & $29(28.2)$ & $29(28.8)$ & $28(28.1)$ & $28(28.3)$ \\
\hline Self-esteem score ${ }^{c}$ Median (Mean) & $24(23.9)$ & $24(23.8)$ & $24(23.6)$ & $24(23.7)$ \\
\hline Body image score ${ }^{\mathrm{d}}$ Median (Mean) & $22(21.1)$ & $22(20.9)$ & $22(21.0)$ & $22(21.2)$ \\
\hline Ever had sex, n (\%) & $34(9.0)$ & $46(12.1)$ & $25(5.2)$ & $36(7.4)$ \\
\hline
\end{tabular}

${ }^{a}$ Sexual health knowledge was a summation of knowledge on pubertal changes, knowledge on how HIV is acquired, and contraception, with a maximum possible score of 25 (actual score range 1 to 20)

${ }^{\mathrm{b}}$ Gender norms were assessed using items from the Attitudes Towards Women Scale and selected context specific gender attitudes on a 4-point likert scale, with a maximum possible score of 44 for 11 items (actual score range 16 to 39)

'Self esteem was estimated using a modified version of the Rosenberg scale, including 7 out of 10 items in the original scale, with a maximum possible score of 28 (actual score range 15-28)

${ }^{\mathrm{d}}$ Body image score was estimated using a self-reported Body Image State Scale (BISS) with 5 of the original 6 items on a 5 -point likert scale with a maximum possible score of 25 (actual range to 12-25) 
Table 5 Bivariate and multivariate comparison of changes from baseline to endline using ordered logistic regression

\begin{tabular}{lll}
\hline Outcome & Bivariate OR $(95 \% \mathrm{Cl})$ & Multivariate AOR (95\% Cl) \\
\hline SRH Knowledge & $2.14(1.64-2.79)^{* *}$ & $2.18(1.66-2.86)^{* *}$ \\
Gender Equitable Norms & $1.12(0.81-1.56)$ & $1.14(0.80-1.62)$ \\
Self Esteem & $0.94(0.65-1.35)$ & $0.93(0.64-1.33)$ \\
Body Image & $0.85(0.56-1.29)$ & $0.84(0.54-1.31)$ \\
Sexual Activity $^{\mathrm{a}}$ & $0.76(0.33-1.75)$ & $0.76(0.32-1.80)$ \\
\hline
\end{tabular}

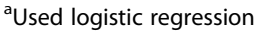

**P $=<0.001$

"When you haven't reached to some stages, there are things they teach and you take them for granted because you haven't experienced anything....There were things they would say and we become shy and refuse to respond like shaving armpits and private parts. When we reached third term, our teachers also taught them to us and there, we became active and responded because we had heard about them before. Now we cannot hide anything." (Student, IDI, rural school)

\section{"...Previously, like a male teacher discussing} menstruation would generate murmurs in the classroom... but now when you speak those words that were previously thought of as taboo, the children do not even blink; they are informed. "(Teacher, IDI, rural school)

As noted in the quantitative results, there were no significant differences in sexual behaviours between the intervention and control groups, due in part to the fact that in this young age group there were low rates of sexual activity in both the intervention and control arms. However, in IDIs and FDGs, pupils reported that the CSE sessions influenced their intention to delay sexual intercourse until they were older to prevent unwanted pregnancy, HIV and other STIs, and that the sessions had increased their perception of SRH related risks. In their FGD, parents also gave similar narratives of what the pupils had shared with them regarding their experiences during the CSE sessions about the knowledge on SRH risks that they had acquired:

"...she told me that yesterday they studied about pregnancy. I asked her what pregnancy means, 'were they telling you to go and conceive?' So she started telling me that they taught them about the challenges you meet when you get pregnant when you are still a young girl." (Parent, FGD, urban)

The participants also revealed that CSE had a positive effect on some of the socio-cognitive determinants of safe sexual behaviour. Self-esteem and decision making were predominantly reported by the participants. Although participants did not detail lived experiences where they applied self-esteem and decision making, the majority gave positive self-reported statements like the following:

"I enjoyed self-esteem because before I never believed in myself and now I do and I can make my own decisions." (Student, FGD, urban school)

Reports on gender and equitable norms were erratic during the pupil's interviews. Examples of gender equitable statements included: "pregnancy and reproduction were the responsibility of both boys and girls," (Student, FGD, Urban school) suggesting that students came to better understand that boys and girls were both responsible for and affected by unwanted pregnancy. While students made statements suggesting they understood the importance of gender and equity in the context of the CSE lessons, they did not explicitly discuss how the lessons influenced their attitudes around gender.

\section{Discussion}

This study aims to evaluate the effectiveness of a Comprehensive Sexuality Education intervention among very young adolescents in primary schools in Uganda. This study is among few studies in Uganda to evaluate a reproductive health intervention among very young adolescents. It contributes to an important but limited body of knowledge regarding SRH programming for very young adolescents. The quantitative results of this study show that pupils in the intervention group were two times more likely than those in the control group to have significantly improved scores in SRH knowledge at the endline. However, there were no significant differences between intervention and control groups in the changes in scores on body image, self-esteem, or gender equitable norms, and there was minimal reporting on changes related to these topics in the qualitative data. Although there were no differences quantitatively in sexual behavior, the qualitative data suggested changes in other behaviors related to $\mathrm{SRH}$, such as behavioral intentions and increased perception of SRH related risks. 
The finding that CSE interventions can lead to immediate improvements in SRH knowledge has been similarly reported in several other related interventions [13, 30]. However, almost all of these studies focus on older adolescents. Our study highlights the fact that even very young adolescents have great improvements in knowledge following a CSE intervention. This change is important in this context because Uganda's young people lack comprehensive SRH knowledge, which has been reported in the DHS [6]. Although knowledge does not equate to behavior change, it is a necessary prerequisite. This is important given the young age of these students, who are just beginning to be exposed to SRH risks.

A higher percentage of pupils in the intervention group were sexually active at baseline, which could relate to statistically significant differences in socioeconomic level $(p<0.01)$, urban/rural distribution $(p<0.001)$, or other individual- or school-level factors. Although other studies have found that CSE can reduce risky sexual behaviors [13, 30], our study found no significant differences in sexual behavior between the treatment and control groups. This is likely due in part to the fact that sexual behavior was uncommon among this relatively young group to begin with; only $9.0 \%$ of the intervention group and $5.2 \%$ of the control group had ever had sex at the beginning of the intervention. Common $\mathrm{SRH}$ outcome measures such as sexual initiation, number of sexual partners and condom use that may apply to older adolescents were found less useful when applied to young adolescents in this study who were mostly sexually naïve. Because sexual activity is not very common, it may have been valuable to explore other behaviors related to sexual and reproductive health that are more relevant to this age group. It is important to note that CSE did not lead to more respondents in the intervention group than control group becoming sexually active at the end of the intervention. This finding is important for policy and programming purposes to improve uptake of CSE among decision makers who believe that addressing adolescent sexuality will lead to more young people engaging in sexual activity. The qualitative results highlight age appropriate information regarding benefits of CSE, such as dispelling fears and anxiety in dealing with puberty changes, recognition of SRH risks and how they can be avoided. This study may have benefitted from exploring other sexual behaviors more relevant to this age group, such as precursors to sex, which some similar impact evaluations among this age group have explored [31]. Finally, because pupils were interviewed right after completion of the intervention, long-term behavioral changes might not yet be present and could not be ascertained.

Additionally, while most of these pupils were not sexually active, in focus group discussions and interviews, several pupils discussed behavior intentions. Pupils reported on their intentions to avoid early pregnancy and STIs and to avoid situations that may lead to sexual violence. Even though many of these adolescents had not yet been faced with these decisions, their intentions and skills in future decision making may have changed. Although behavior intention does not necessarily lead to direct behavior change, a meta-analysis of 47 RCTs of behavior change found that medium to large changes in behavior intention do lead to small to medium changes in behavior [32]. Our qualitative data suggest that SRH research among this young age group may provide more meaningful results if it examines behavior intention, and other behaviors related the SRH that are more relevant in this young age group.

This study evaluated dimensions of sexual wellbeing, including gender equitable norms, self-esteem and body image, in order to assess the positive aspects of CSE, as opposed to exclusively assessing risk behaviors. This is one of the first studies to evaluate a CSE intervention in Uganda using these measures, especially among this age group. These measures have been advocated for by experts including the WHO and the European Sexuality Education Expert group, who believe that data on sexual wellbeing can provide important information on the impact of these programs that is often overlooked. However, we did not find any differences between the intervention and control groups, and in fact, there were almost no changes between baseline and endline among either group. This may be attributed to the short interval between the intervention and evaluation, as skill and attitudes take a longer time to change. Also, notably as we described earlier, the initial scores per group for selfesteem and body image were very high [28], leaving limited room for significant improvement. It might be valuable to follow up with these pupils as they get older, when self-esteem and body image tend to vary more [33]. Additionally, measures should be developed that are more tailored to this age group.

This study had several limitations, including a short time interval between the intervention and evaluation. During the study implementation the political environment for sexuality education was prohibitive and essentially a ban was instituted on non-research related dissemination of sexuality education in schools [34]. Although we were able to continue our programming, this prohibitive environment could have affected delivery and/or uptake of the information. Furthermore, the fact that the study population was mostly sexually naive made it difficult to assess changes in sexual behavior using common measures, such as condom use. We were able to overcome this by establishing qualitative data on applicable behavioral intentions and reporting, but did not measure these alternative outcomes quantitatively. 
Finally, we did not collect qualitative data among the control students, and are therefore unable to compare qualitative feedback between the two groups.

\section{Conclusion}

This study provides insights regarding the value of implementing SRH education among very young adolescents. It was found that even among these very young adolescents, this intervention led to significant improvements in knowledge. Although knowledge is not sufficient to drive behavior change, it is an important prerequisite for behavior change to occur as adolescents get older. Although we saw no quantitative differences between the intervention and control arms in sexual behavior, and very little sexual behavior overall, the qualitative data suggested changes in behavior intention that could decrease risky sexual behaviors as adolescents get older. More so, it was noted that CSE did not increase sexual activity in the intervention group, which has been a concern among some policy makers in Uganda. This study contributes to the limited body of knowledge on CSE interventions among very young adolescents in Uganda, highlighting the subtle but important advantages of starting this kind of programming at a young age.

\section{Supplementary information}

Supplementary information accompanies this paper at https://doi.org/10. 1186/s12889-019-7805-y.

Additional file 1. Interview guide for the study.

\section{Abbreviations}

CSE: Comprehensive Sexuality Education; FGD: Focus Group Discussion; IDI: In Depth Interview; RA: Research Assistant; SRH: Sexual and Reproductive Health; SSA: Sub Saharan Africa; WYA: Very Young Adolescent

\section{Acknowledgements}

We wish to thank all the research assistants who participated in the survey, including Ruth Kaziga, Charlotte Achen and Clara Tibeihaho. We also thank Rinah Arinaitwe and her team for the data management. We acknowledge the contribution of Damazo Kadengye and Daniel Atwine for their statistical input throughout the course of the project. Finally, we thank Cecilia Akatukwasa for her contribution towards the qualitative analysis of the project. The acknowledged persons gave full permission for their names to be published.

\section{Authors' contributions}

EK and KB participated in data analysis and drafting the initial manuscript VNN, KM participated in data analysis and editing of the manuscript. Ol, EL, GC, GNR, ABN and WM edited and revised the manuscript. All authors approved the final manuscript.

\section{Funding}

This study was funded by Flemish Interuniversity Council (VLIR UOS) under a team project, grant number ZEIN2015PR411. The funders had no role in the study design, data collection procedures or writing of the manuscript.

\section{Availability of data and materials}

The datasets analysed during the current study are available from the corresponding author on reasonable request.

\section{Ethics approval and consent to participate}

Ethical approval was received from the Mbarara University Research Ethics Committee (REF MUIRC/7) and Uganda National Council of Science and Technology (SS 4045) as well as Ghent University Hospital Ethics Board. We obtained written informed consent from the school head teachers and parents/guardians and assent from pupils prior to data collection.

Authorization was obtained from the local ethics board to allow teachers to consent as legal guardians for pupils if a parent was not available at the time of the interview, and efforts were made to inform these parents of their child's participation.

\section{Consent for publication \\ Not Applicable.}

\section{Competing interests}

The authors declare that they have no competing interests.

\section{Author details}

${ }^{1}$ Mbarara University of Science and Technology, P.O. Box 1410, Mbarara, Uganda. ${ }^{2}$ International Centre for Reproductive Health, Faculty of Medicine and Health Sciences, Ghent University, Ghent, Belgium. ${ }^{3}$ Division of Infectious Diseases and Tropical Medicine, Medical Centre of the University of Munich (LMU), 80802 Munich, Germany. ${ }^{4}$ Centre of Expertise on Gender, Diversity and Intersectionality, Vrije universiteit Brussels, Brussels, Belgium.

Received: 16 August 2018 Accepted: 17 October 2019

Published online: 28 October 2019

\section{References}

1. UNFPA. Demographic Dividend https://www.unfpa.org/demographicdividend accessed 14th April 2019. Available from: https://www.unfpa.org/ demographic-dividend Accessed 14 Apr 2019

2. Patton GC, Sawyer SM, Santelli JS, Ross DA, Afifi R, Allen NB, et al. Our future: a lancet commission on adolescent health and wellbeing. Lancet. 2016;387(10036):2423-78.

3. WHO. Health for the world's adolescents. A second chance in the second decade. Geneva; 2014. http://apps.who.int/adolescent/second-decade/: Accessed 20 Mar 2018.

4. UNICEF. Adolescent demographics. 2016. https://data.unicef.org/topic/ adolescents/demographics/ Accessed 4 Oct 2019.

5. Woog $\vee$, Kågesten $A$. The sexual and reproductive health needs of very young adolescents aged 10-14 in developing countries: what does the evidence show? New York: Guttmacher Institute; 2017.

6. Uganda Bureau Of Statistics (UBOS) and ICF. The Uganda Demographics and Health Survey 2016: Key Indicators Report. Kampala; 2017. http:// dhsprogram.com/pubs/pdf/FR333/FR333.pdf. Accessed 15 July 2018.

7. Azevedo WF, Diniz MB, Fonseca ESVB, Azevedo LMR, Evangelista CB. Complications in adolescent pregnancy: systematic review of the literature. Einstein (São Paulo). 2015;13(4):618-26.

8. Malamitsi-Puchner A, Boutsikou T. Adolescent pregnancy and perinatal outcome. Pediatr Endocrinol Rev. 2006;3:170-1.

9. UPHIA(2016-2017). Uganda Population Based HIV Impact Assessment 2017 [21 June 2018]. Available from: http://www.afro.who.int/sites/default/files/2 017-08/UPHIA\%20Uganda\%20factsheet.pdf. Accessed 21 June 2018.

10. Ninsiima AB, Leye E, Michielsen K, Kemigisha E, Nyakato VN, Coene G. "Girls Have More Challenges; They Need to Be Locked Up": A Qualitative Study of Gender Norms and the Sexuality of Young Adolescents in Uganda. Int J Environ Res Public Health. 2018;15(2):193.

11. WHO. Adolescent pregancy: http://www.who.int/en/news-room/factsheets/detail/adolescent-pregnancy; 2018. Available from: http://www. who.int/en/news-room/fact-sheets/detail/adolescent-pregnancy. Cited 201821 June 2018

12. UNESCO. International Technical Guidance on Sexuality Education; An evidence- informed approach for schools teachers and health educators. 2009. http://unesdoc.unesco.org/images/0018/001832/183281e.pdf:.

13. Fonner VA, Armstrong KS, Kennedy CE, O'Reilly KR, Sweat MD. School based sex education and HIV prevention in low-and middle-income countries: a systematic review and meta-analysis. PLoS One. 2014;9(3):e89692.

14. Kinsman J, Nakiyingi J, Kamali A, Carpenter L, Quigley M, Pool R, et al. Evaluation of a comprehensive school-based AIDS education programme in rural Masaka, Uganda. Health Educ Res. 2001;16(1):85-100. 
15. Michielsen K, Beauclair R, Delva W, Roelens K, Van Rossem R, Temmerman M. Effectiveness of a peer-led HIV prevention intervention in secondary schools in Rwanda: results from a non-randomized controlled trial. BMC Public Health. 2012;12(1):729.

16. Rijsdijk LE, Bos AE, Ruiter RA, Leerlooijer JN, de Haas B, Schaalma HP. The world starts with me: a multilevel evaluation of a comprehensive sex education programme targeting adolescents in Uganda. BMC Public Health. 2011;11(1):334.

17. Michielsen $K$, Chersich MF, Luchters $S$, De Koker P, Van Rossem R, Temmerman M. Effectiveness of HIV prevention for youth in sub-Saharan Africa: systematic review and meta-analysis of randomized and nonrandomized trials. Aids. 2010;24(8):1193-202.

18. Ketting E, Friele M, Michielsen K, Education EEGoS. Evaluation of holistic sexuality education: a European expert group consensus agreement. Eur J Contracept Reprod Health Care. 2016;21(1):68-80.

19. Ajzen I. The theory of planned behavior. Organ Behav Hum Decis Process. 1991;50(2):179-211.

20. Bronfenbrenner U. Ecological models of human development. Read Dev Child. 1994;2(1):37-43.

21. Organization WH. Standards for sexuality education in Europe: a framework for policy makers, educational and health authorities and specialists. Federal Centrefor Health Education, BZgA: Cologne; 2010.

22. Gertler PJ, Martinez S, Premand P, Rawlings LB, Vermeersch CM. Impact evaluation in practice: World Bank publications; 2016.

23. Schulz KF, Altman DG, Moher D. CONSORT 2010 statement: updated guidelines for reporting parallel group randomised trials. BMC Med. 2010;8(1):18.

24. Cleland J. Illustrative questionnaire for interview-surveys with young people. Asking Young People About Sexual and Reproductive Behaviors Illustrative Core Instruments. Geneva: World Health Organization; 2001.

25. Rosenberg M. Rosenberg self-esteem scale (RSE). Acceptance and commitment therapy Measures package, vol. 61; 1965. p. 52.

26. Cash TF, Fleming EC, Alindogan J, Steadman L, Whitehead A. Beyond body image as a trait: the development and validation of the body image states scale. Eat Disord. 2002;10(2):103-13.

27. Galambos NL, Petersen AC, Richards M, Gitelson IB. The attitudes toward women scale for adolescents (AWSA): a study of reliability and validity. Sex Roles. 1985:13(5):343-56

28. Kemigisha E, Nyakato VN, Bruce K, Ndaruhutse Ruzaaza G, Mlahagwa W, Ninsiima AB, et al. Adolescents' sexual wellbeing in southwestern Uganda: a cross-sectional assessment of body image, self-esteem and gender equitable norms. Int J Environ Res Public Health. 2018;15(2):372.

29. Kemigisha E, Ivanova O, Ruzaaza GN, Ninsiima AB, Kaziga R, Bruce K, et al. Process evaluation of a comprehensive sexuality education intervention in primary schools in South Western Uganda. Sex Reprod Healthc. 2019;21:51-9.

30. Salam RA, Faqqah A, Sajjad N, Lassi ZS, Das JK, Kaufman M, et al. Improving adolescent sexual and reproductive health: a systematic review of potential interventions. J Adolesc Health. 2016;59(4):S11-28.

31. Kaufman CE, Schwinn TM, Black K, Keane EM, Big Crow CK, Shangreau C, et al. Impacting precursors to sexual behavior among young American Indian adolescents of the Northern Plains: a cluster randomized controlled trial. J Early Adolesc. 2018;38(7):988-1007.

32. Webb TL, Sheeran P. Does changing behavioral intentions engender behavior change? A meta-analysis of the experimental evidence. Psychol Bull. 2006;132(2):249

33. Clay D, Vignoles VL, Dittmar H. Body image and self-esteem among adolescent girls: testing the influence of sociocultural factors. J Res Adolesc. 2005:15(4):451-77.

34. URN. MPs Demand Ban on Sex Literature in Schools: https:// ugandaradionetwork.com/story/mps-demand-withdraw-of-sex-education-inschools; 2016. Available from: https://ugandaradionetwork.com/story/mpsdemand-withdraw-of-sex-education-in-schools. Cited 2018 July 112018.

\section{Publisher's Note}

Springer Nature remains neutral with regard to jurisdictional claims in published maps and institutional affiliations.

Ready to submit your research? Choose BMC and benefit from:

- fast, convenient online submission

- thorough peer review by experienced researchers in your field

- rapid publication on acceptance

- support for research data, including large and complex data types

- gold Open Access which fosters wider collaboration and increased citations

- maximum visibility for your research: over $100 \mathrm{M}$ website views per year

At BMC, research is always in progress.

Learn more biomedcentral.com/submissions 